appointments on April 17 and announced that the Council's Administrative Committee had granted Executive Director Catherine Rudder a six-month sabbatical leave to begin in mid-September. Rudder intends to use her leave in part to work on the strategic planning initiative adopted by the APSA Council.

Appointed to the Ad Hoc Committee on Political Science and the National Science Foundation are Frank Sorauf (chair), University of Minnesota; Susan Welch, Pennsylvania State University; Michael Dawson, University of Chicago; Lee Sigelman, George Washington University; Arthur Lupia, University of California, San Diego; Miriam Golden, University of California, Los Angeles; and Stephen Walt, University of Chicago. The Committee has been charged by the Council to evaluate the discipline's relationship with NSF.

In addition to confirming the ad hoc committee appointments, Council members accepted assignments to the Administrative, Elections and Rules Committees of the Council and confirmed the following Association members as APSA representatives to other organizations:

- Carol Nechemias, Pennsylvania State University, Harrisburg, Association for the Advancement of Slavic Studies

- Ronald Kahn, Oberlin College, American Council of Learned Societies

- Sidney Verba, Harvard University, Social Science Research Council

\section{Strategic Planning Initiative Set by Council}

Approving a recommendation by the Administrative Committee, the Council agreed at its April 17 meeting to institute a strategic planning process to chart APSA's future. President Matthew Holden and President-Elect Robert Keohane brought the proposal forward for the Council's consideration. In the memorandum explaining the reasons for initiating a systematic rethinking of APSA's activities, executive director Catherine Rudder offered eight reasons, including:
1. Associations in general are experiencing declines in participation. In the case of APSA, membership has dropped for two years in a row.

2 . The results of two surveys, one of members and the other of former members, question the relevance of many APSA programs and services and suggest dissatisfaction in particular areas.

3. APSA is operating under increasingly constrained financial conditions, as evidenced by a budget that is perilously tight and that cannot sustain any new activities without significant new revenue streams.

4. The dramatic transformation in information technology goes to the heart of the work of our societyscholarly communication. It is fundamentally altering the economics of communicating and the ways in which communication takes place. This change affects virtually everything the Association does and requires a reconsideration (already well underway) of practices that have served APSA members well in the past but which are not adequate for the digital world.

5. Increasing demands are being made for new services without equal attention being paid to the resources needed to support those services appropriately. For example, the size of the Annual Meeting and the services underpinning the meeting have been expanded without commensurate increases in financial support. As a result, the workload of the Program Committee and the national office is onerous.

6 . The adequacy of governance structures needs to be assessed. For example, expectations of rapid response from decision-making bodies have begun to emerge, with the result that a Council that meets twice a year and committees that meet once a year may seem unresponsive.

7. The political science profession may be experiencing a declining sense of community, as evidenced by, for example, an apparent desire only to pay for the services one wants and receives, which would constitute a noteworthy shift from the idea that one joins a scholarly society to support one's discipline.

8. Political science is developing rapidly in other parts of the world and the Association should be in a position to facilitate that development to as great a degree as possible.

The memo concluded that to face these and other challenges appropriately and to seize the opportunities that both the digital revolution and the internationalization of political science offer, strategic planning should seriously be considered by the Council. A process of this sort requires serious thought among the Association's leaders, as well as its members and staff.

The Council approved a tentative timetable that would have the executive director consult extensively with the Association's leaders, members, and staff and then develop an agenda for the process, including substantive topics to be covered, data to be gathered, a proposed budget, a detailed plan, and suggestions for the types of people who might be involved to ensure that the breadth of the discipline and of members' concerns are covered. This document is to be presented to the Council at its September meeting for the Council's approval.

\section{Council Holds Firm on Coursepack Permissions Fees}

At its April 17 meeting, APSA's Publications Committee reported back to the Council on the Council's September 2, 1998 request to consider eliminating classroom use permissions fees. Publications Committee Chair Bert Rockman and Committee member Richard Brody, chair of the PS Editorial Board, presented their findings to APSA's governing body.

Rockman and Brody said that the Committee's deliberations focused on three issues: 1) the principle of free access to Association publications; 2) the possibility that permissions fees create a financial burden on students; and 3) the impact on APSA revenue and programs.

\section{Access to Political Science Scholarship}

The Committee's consensus was that the Association provides ample free 
access to its journals. Coursepacks are not the only means of access to APSA materials and are merely a convenience for students. The Association's journals, whose articles constitute the majority of permissions requests, are freely available in a number of formats. Current issues of both APSR and PS are available online through university and college library electronic subscriptions to UMI and OCLC. The backfile of APSR (from 1906 to 1995 ) is available through JSTOR. Students continue to have the option of photocopying articles from the print versions of both journals. Finally, APSA's permission policy allows professors to place copies of any article on reserve (print or electronic) free of charge for the use of students.

\section{Impact of Permissions Fees on Students}

Committee members recognized that permissions fees might increase the cost of coursepacks for students considerably in those instances when faculty require their purchase.

To determine the burden on students, committee members asked APSA staff members to determine the burden of permission fees on students using activity reports provided to the Association by CCC. Detailed information on CCC permissions requests and the costs to students collected by APSA staff indicates that the costs students must bear are low.

Committee members also recognized that coursepacks are often used in lieu of textbooks: rather than presenting a new cost for students, coursepacks are often a replacement cost. Most Committee members also noted that $A P S R$ and $P S$ articles do not make up the bulk of most coursepacks and that eliminating permissions fees would not dramatically affect the cost of a coursepack.

\section{Impact of Permission Fees on APSA Revenue}

These permission fees (projected to be $\$ 18,000$ for FY99 and growing each year) support Association activ- ities. Committee members acknowledged that eliminating this revenue would affect APSA services. The Association would have to eliminate programs or seek new sources of revenue. Committee members discussed raising membership dues by $\$ 1.50$ to recover the revenue but acknowledged that making members underwrite the use of articles by students is not an attractive option.

Rockman and Brody reported that it was the sense of the Committee that there are various, and widely available ways, to freely access APSA's journals, and that the cost of permissions fees is widely distributed and presents a minimal burden to a large group of individuals. However, the revenue generated by classroom permission fees is significant to the operation of the Association and its programs. The Committee felt that eliminating permission fees would negatively impact the Association but would not significantly decrease the cost of coursepacks to students and asked the staff to provide more conclusive evidence that this determination was correct.

As requested, in the materials presented to the Council were the reports from the Copyright Clearance Center, which processes the predominance of coursepack permissions requests, for 1998 in order to determine more precisely the financial burden that permissions fees for APSA publications creates for students. Analysis of CCC's reports confirmed what the Publications Committee suspected: The burden placed on an individual student by APSA permissions fees is quite low. In each quarter, more than $55 \%$ of students paid for only one article $(\$ 0.75)$.

Of the requests for 204 classes, ${ }^{1}$ only 9 were for six or more articles. Students paying for six or more articles were typically graduate students. Since Ph.D. institutions are most likely to have electronic access to the $A P S R,{ }^{2}$ Ph.D. faculty have the option of requiring graduate students to access the articles electronically. Additionally, as the APSA permission policy allows libraries to keep up to 10 copies of an article on reserve, ${ }^{3}$ there can be sufficient paper copies of articles available to graduate students. By comparison, 130 requests were for classes using one article only.

After some discussion, the Council voted to continue existing policy.

Notes:

1. For the period October 1997 through September $1998,88.6 \%$ of the requested articles were from the American Political Science Review, $10.8 \%$ were from PS: Political Science and Politics, and the remaining requests were from The State of the Discipline.

2. Of the 80 institutions seeking permission to use articles during the period October 1997 to September 1998, 70 have subscriptions to JSTOR.

3. The current Association policy allows for fair use of articles by levying no fee for the first ten copies of a printed article, whether in course packs or on reserve. Smaller classes, that rely heavily on articles (i.e., upper level undergraduate and graduate classes) can take advantage of this provision. APSA policy also permits free use of electronic library reserve with no limit on the number of students who can access the electronic reserve. Both large and small classes that rely on articles can take advantage of this provision.

\section{Council Makes Members Eligible for APSR Online Archive}

APSA's Council has approved a plan proposed by the Publications Committee to offer individual members access to the APSR online archive that extends from 1906 through 1996. Currently, this fully searchable database, along with 100 other scholarly journals, is available only to subscribing libraries through JSTOR, a nonprofit organization initiated by the Mellon Foundation. JSTOR has now agreed that APSA can offer its members access to the APSR portion of the larger collection.

Beginning with the June membership dues renewal notice, APSA members will be given the opportunity to subscribe to the archive for $\$ 25$ annually. Subscriptions will be offered coterminously with membership. Each year, the next consecutive volume of $A P S R$ will be added to the collection. For example, the 1997 volume will become available in 2000 .

The Publications Committee cited 